\title{
Correlation between clinical-functional parameters and number of lobes involved in non-cystic fibrosis bronchiectasis
}

\author{
Valeria Giacon, ${ }^{1}$ Stefano Sanduzzi Zamparelli, ${ }^{1}$ Alessandro Sanduzzi Zamparelli,, ${ }^{1,2}$ Dario Bruzzese, ${ }^{3}$ \\ Marialuisa Bocchino ${ }^{1}$ \\ ${ }^{1}$ Section of Respiratory Disease, Department of Clinical Medicine and Surgery, Monaldi Hospital, University Federico II of \\ Naples \\ ${ }^{2}$ Staff of United Nations Educational, Scientific and Cultural Organization (UNESCO), Health Education and Sustainable \\ Development, University Federico II of Naples \\ ${ }^{3}$ Department of Public Health, University Federico II of Naples, Italy
}

\begin{abstract}
Background: Currently, the prognosis of bronchiectasis is based on different prognostic indicators, like BSI and FACED score, founded on clinical-demographic, functional and radiological criteria. Both scoring systems include the number of lobes involved in bronchiectasis, which represents an adverse prognostic index. Our study aimed to investigate the prognostic role of the clinical-functional parameters and the number of involved lobes ratio in adult bronchiectasis.

Methods: The study was conducted on 52 patients diagnosed with non-cystic fibrosis bronchiectasis (NCFB) between 2015 and 2017 who attended the Pneumology Unit of Monaldi Hospital in Naples, Italy. Correlations between clinical-functional parameters (BMI, smoking history, number of exacerbations in the previous year, spirometry, $\mathrm{DL}_{\mathrm{CO}}$, ABG test, and 6MWT) and number of involved lobes were investigated.

Results: At baseline, the number of exacerbations in the previous year had a statistically significant association with the number of involved lobes. Furthermore, at baseline, the radiological criterion was also negatively associated with some functional parameters $\left(\mathrm{FEV}_{1} / \mathrm{FVC}\right.$ ratio e $\left.\mathrm{FEF}_{25-75 \%}\right)$. Statistical significance was lost during the follow up, demonstrating the effectiveness of the therapy.

Conclusions: Imaging extension represents a promising biomarker of disease severity as well as a helpful follow up tool for non-Cystic Fibrosis bronchiectasis (NCFB).
\end{abstract}

Key words: Bronchiectasis; HRCT; lobe; pulmonary function tests; exacerbations; NCFB.

Correspondence: Prof. Alessandro Sanduzzi Zamparelli, Section of Respiratory Disease, Department of Clinical Medicine and Surgery, Monaldi Hospital, University Federico II of Naples, Piazzale Ettore Ruggeri, 80131 Naples, Italy.

Tel. +39.081.7065200 - Fax: +39.081.7702457. E-mail: sanduzzi@unina.it

Contributions: VG, manuscript drafting; SSZ, MB, manuscript revision; ASZ, database examination; DB, statistical analysis, performing. All the authors have read and approved the final version of the manuscript and agreed to be accountable for all aspects of the work.

Funding: This research did not receive any specific grant from funding agencies in the public, commercial, or not-for-profit sectors.

Conflict of interest: The authors declare that they have no competing interests, and all authors confirm accuracy.

Availability of data and materials: The datasets used and/or analyzed during the current study are available from the corresponding author on reasonable request.

Ethics approval and consent to participate: The study is exempt from the Ethical Committee approval as it did not involve any specific protocols other than routine investigations. Informed consent was not required since patients enrolled in the study underwent routine investigations. 


\section{Introduction}

The term "bronchiectasis" indicates a permanent and irreversible dilation of the bronchial wall, associated with the occurrence of cough, dyspnoea, daily production of sputum, and recurrent respiratory infections [1]. Intraluminal neutrophils, having come into contact with the aetiological agent, produce inflammatory mediators, destroying elastin, cartilage, and muscles of the large airways, with consequent irreversible bronchodilation. Besides, macrophages and lymphocytes form infiltrates in the inflamed airways. Repeated damage causes a thickening of the bronchial walls, formation of mucus plugs, and the presence of varying degrees of hyperinflation [2]. It has a huge social-health impact, caused mainly by frequent hospitalizations and mortality $[3,4]$. The overall prevalence of bronchiectasis in the Italian population, according to data provided by general practitioners (GPs), is 163 per 100,000 , whereas annual incidence is 16.3 per 100,000 person-years [5]. Both prevalence and incidence increase with age, with the highest rates reported in patients aged $>75[5]$.

The aetiology of non-cystic fibrosis bronchiectasis (NCFB) differs between childhood and adulthood. The localized forms are mostly secondary to chronic obstructive factors, represented in the child by the accidental aspiration of a foreign body. In adults, localized forms of NCFB are caused by infections or tumour pathology, generally benign. Both age groups may be subjected to obstruction due to the inflammatory-infectious hypertrophy of the peri-interbronchial lymph nodes.

In the aetiology of diffuse forms, the alteration of the pulmonary defence mechanisms prevails due to primary immunodeficiency, detected in the dysgammaglobulinemia, or by altered mucociliary clearance due to ciliary dyskinesia, systemic disorders (systemic lupus erythematosus, rheumatoid arthritis, Sjögren syndrome, inflammatory bowel disease) or alteration of the rheological characteristics of secretions and facilitated bacterial adhesiveness, as observed in cystic fibrosis (CF) [6]. However, very often, NCFB remains idiopathic (40-50\%).

Mucus removal and local defence mechanisms against microorganisms are essential in keeping the lungs free from infections [2]. When these mechanisms are impaired, exacerbations worsen inflammation, resulting in fibrosis and dilation of the bronchial wall. Therefore, there is a progressive decrease in respiratory function, confirmed by spirometry. Usually, $\mathrm{FEV}_{1}$ declines according to the disease's progression, and thus it might be preferred for monitoring bronchiectasis [7]. Likewise, both arterial blood gas analysis (ABGs) and diffusing capacity of the lung for $\mathrm{CO}\left(\mathrm{DL}_{\mathrm{CO}}\right)$ may be abnormal due to these alterations.

The 6-minute walking test (6MWT) is a sub-maximal, simple exercise test used to assess the respiratory system's functional responses during physical effort, representing a helpful index of the aerobic capacity of bronchiectasis patients [8]. Of course, early diagnosis allows for quick and targeted treatment that improves the long-term prognosis.

Chest high-resolution computed tomography (HRCT) of the chest is currently the gold standard for correct diagnosis and staging of the lesions, assessing morphological aspects, localization, and extent of wall damage. Furthermore, it is useful to evaluate complications, such as emphysema and pulmonary hypertension. The latter condition can be identified early by measuring the pulmonary artery's cross-sectional area and comparing it to that of the aorta (AP/A ratio is strictly linked to the mean pulmonary artery pressure value) [9]. Emphysema can be identified by CT scans as low attenuation areas (LAA) with a different degree of vascular compartment involvement [9]. Also, thin slice reconstructions are preferred to detect lesions smaller than $5 \mathrm{~mm}$ and visualize the "air-trapped" areas [9]. Upper lobe predominance is seen in sarcoidosis, aspergillosis, post-tuberculous scarring, and post-radiation fibrosis. Calcified hilar or mediastinal lymph nodes and calcified pulmonary granulomas suggest granulomatous infections, such as tuberculosis [6]. Anterior segment distribution (middle lobe and lingula) is generally observed in atypical mycobacterial disease, which usually involves two or more lobes and often affects middle-aged or elderly female patients [6]. Lower lobe distribution is most often seen in post-infectious bronchiectasis, chronic aspiration, immunodeficiencies, and primary ciliary dyskinesia [6].

The significant aetiological variability of bronchiectasis could explain the different extent of lesions in the lung lobes. Immunodeficiencies, genetic diseases, chronic colonization by multidrug-resistant strains of Pseudomonas aeruginosa, tuberculous and non-tuberculous mycobacterial infections are examples of conditions that predispose the onset of bronchiectasis [6]. These often have a severe prognosis due to the high number of annual exacerbations and the rapid deterioration of respiratory function towards lung failure, as confirmed by this study.

The analysis carried out in this study is focused on the relationship between clinical-functional parameters and imaging, examining the correlations among clinical data, lung function tests, and the number of lobes affected by bronchiectasis on chest HRCT. Functional data of interest were collected at baseline and at three and six months.

\section{Methods}

\section{Study population}

The study population included 52 adults diagnosed with NCFB referred to our Respiratory Medicine Unit at the Monaldi Hospital in Naples, Italy, between December 2015 and October 2017. Lung function testing and chest HRCT were available for all patients along with clinical data. The inclusion criteria were:

Age $\geq 18$

Chest HRCT confirmed diagnosis;

Exclusion of cystic fibrosis history.

\section{Baseline clinical data}

Fifty-two patients with an average age of $55.8 \pm 17.3$ years $(21$ to 81 years) were enrolled (Table 1). Main anamnestic data, including smoking habits and the recurrence of exacerbations in the previous year, were collected at enrolment. Thirty-two (61.5\%) were females, twenty $(38.5 \%)$ were male. There were seventeen former smokers $(32.7 \%)$, six current smokers $(11.5 \%)$, and twenty-eight non-smokers $(55.8 \%)$.

Eleven patients $(28.9 \%)$ reported no exacerbation in the previous year, thirty-tree patients $(50 \%)$ reported one exacerbation, and eight $(21.1 \%)$ reported more than one. Thirteen patients $(25 \%)$ were affected by chronic infection of Pseudomonas aeruginosa.

Twenty patients $(38.5 \%)$ were overweight $(25.0-29.99$ $\left.\mathrm{kg} / \mathrm{cm}^{2}\right)$, five $(9.6 \%)$ had mild obesity $\left(30.0-34.99 \mathrm{~kg} / \mathrm{cm}^{2}\right)$, and two $(3.8 \%)$ had moderate-severe obesity $\left(>35 \mathrm{~kg} / \mathrm{cm}^{2}\right)$.

\section{Pulmonary function tests (PFTs)}

The patients' pulmonary function was investigated through global spirometry, diffusing capacity of the lung for carbon monoxide $\left(\mathrm{DL}_{\mathrm{CO}}\right), 6 \mathrm{MWT}$, and ABGs. Functional data were collected at the first visit and subsequently at 3 and 6 months. Some controls are missing at T3 and T6 because the patients could not perform functional tests or did not show up for the outpatient visit. 


\section{Chest HRCT}

All patients underwent chest high resolution computed tomography. Lingula was considered as a separate lobe [10].

The patients were grouped into two subsets according to imaging criteria: the first group included twenty-nine patients $(55.8 \%)$ with up to 2 involved lobes and the second group consisting of twenty-three patients (44.2\%) with more than 2 affected lobes ( 3 to $6)$. This categorization was designed to make the two groups homogeneous, such that the two groups were quite numerically balanced.

\section{Statistical analysis}

Standard descriptive statistics were used to characterize the overall cohort and the two groups defined, based on the numbers of involved lobes. Numerical variables were described using mean \pm standard deviation (SD) with range, and categorical factors were synthesized using absolute frequencies and percentages. Accordingly, between-group comparisons were based on the Student's $t$-test for unpaired samples and the Fisher exact test.

Longitudinal changes of functional data were assessed using Linear Mixed Models with time (baseline, 3, and 6 months), the number of lobes (1-2 vs 3-6), and their interaction as the only predictors. Results of LMMs were expressed as the difference in the Estimated Marginal Means (EMMs) with the corresponding 95\% Confidence Intervals (95\% CIs). Statistical significance was set at $\mathrm{p}<0.05$; all statistical analyses were conducted using the $\mathrm{R}$ Platform, v. 4.0.1 [11].

\section{Results}

\section{Association between clinical data and number of lobes}

According to the numbers of involved lobes (Table 1), all the patients were classified into two groups: no significant differences were found at baseline in the two groups concerning age, gender, BMI, and smoking habit. Patients with more than two involved lobes were characterized by more exacerbations in the last year $(\mathrm{p}=0.014)$.

\section{Longitudinal change of functional and tomographic parameters}

Plethysmography showed that all patients had lung hyperinflation (Motley Index $>30 \%$ predicted). The pulmonary function tests
(PFTs) were performed according to the American Thoracic Society / European Respiratory Society guidelines [12].

Greater bronchiectasis involvement was found in the lower lobes $(23.5 \%$ in the left lobe and $19.7 \%$ in the right lobe) and in the middle lobe $(22.0 \%)$. The lingula was affected in $14.4 \%$ of cases, the left upper lobe in $9.8 \%$, the right in $10.6 \%$. These data are based on often multi-lobar involvement.

Regarding ABG analysis, only 4 (9.5\%) patients experienced hypoxemia, and there was only one patient with severe hypoxemia. However, twelve patients had altered $\mathrm{PaCO}_{2}$ values: eight (19.0\%) showed an increase, generally associated with a bronchial or bronchiolar obstruction; four $(9.5 \%)$ patients had hypocapnia, a sign of hyperventilation more related to a restrictive or mixed pattern.

At baseline, patients with more than two lobes involved in bronchiectasis showed significantly lower levels of $\mathrm{FEV}_{1} / \mathrm{FVC}$ ratio $(-8.16$; $95 \% \mathrm{CI}$ : -16.18 to -0.14$)$ and $\mathrm{FEF}_{25-75} \%(-20.8 ; 95 \%$ CI: -40.8 to -0.8$)$ (Table 2). No other significant differences were observed, at baseline, in the other functional and tomographic parameters. $\mathrm{FEF}_{25-75} \%$ remained significantly lower in the second evaluation $(-25.13 ; 95 \% \mathrm{CI}:-45.57$ to -4.59$)$, and afterward, mainly due to the decline observed in subjects with less than two involved lobes, the two groups become comparable. No other differences were observed between the two groups during the whole follow up.

\section{Discussion}

The current literature faces two main challenges in the management of bronchiectasis:

- Identifying patients with a high symptomatic burden, at risk of frequent exacerbations or rapid decline in lung function, who may benefit from faster aggressive treatment and closer follow up in reference centres, to reduce possible complications [13]; - Identifying low-risk patients who could benefit from non-specialist follow up or less aggressive treatment regimens to reduce health costs and improve patient satisfaction [13].

The incidence of the disease has undergone a notable increase in recent years. Bronchiectasis is no longer considered a rare condition as it was in the past (16.3:100,000 people per year), possibly due to better quality imaging techniques and more frequent use of HRCT to detect emphysema in COPD patients. The importance of HRCT in the diagnosis and monitoring of bronchiectasis is evident. This is also indicated by the high number of patients $(55.8 \%)$

Table 1. Clinical features and number of lobes involved in bronchiectasis. Values expressed as $\mathbf{n}(\%)$ or as mean \pm SD.

\begin{tabular}{|c|c|c|c|c|c|}
\hline Parameters & All patients & 1-2 lobes & 3-6 lobes & $\mathbf{p}$ & Statistical significance \\
\hline Age, years & $52.55 .8 \pm 17.3(21-81)$ & $2960 \pm 16.1(21-81)$ & $2353 \pm 17.4(21-81)$ & 0.141 & Not significant \\
\hline $\begin{array}{l}\text { Gender } \\
\quad \text { Female } \\
\text { Male }\end{array}$ & $\begin{array}{l}32(61.5) \\
20(38.5)\end{array}$ & $\begin{array}{l}16(55.2) \\
13(44.8)\end{array}$ & $\begin{array}{c}16(69.6) \\
7(30.4)\end{array}$ & 0.39 & Not significant \\
\hline BMI, $\mathrm{kg} / \mathrm{m}^{2}$ & $25.8 \pm 4.4(18.4-42.8)$ & $25.2 \pm 3.4(18.9-33.7)$ & $27 \pm 6(18.4-42.8)$ & 0.221 & Not significant \\
\hline $\begin{array}{l}\text { Smoking } \\
\text { Former smokers } \\
\text { Non-smokers } \\
\text { Smokers }\end{array}$ & $\begin{array}{c}17(32.7) \\
29(55.8) \\
6(11.5)\end{array}$ & $\begin{array}{c}11(37.9) \\
14(48.3) \\
4(13.8)\end{array}$ & $\begin{array}{c}6(26.1) \\
15(65.2) \\
2(8.7)\end{array}$ & 0.608 & Not significant \\
\hline $\begin{array}{l}\text { Exacerbations* (numbe } \\
0 \\
1 \\
>1\end{array}$ & $\begin{array}{l}11(28.9) \\
19(50) \\
8(21.1)\end{array}$ & $\begin{array}{c}7(31.8) \\
14(63.6) \\
1(4.5)\end{array}$ & $\begin{array}{c}4(25) \\
5(31.2) \\
7(43.8)\end{array}$ & 0.014 & Significant \\
\hline
\end{tabular}

BMI, body mass index; *exacerbation in the previous year. 
with limited pulmonary involvement (1-2 lobes).

Another crucial observation concerns the correlation between the number of lobes and functional parameters $\left(\mathrm{FEV}_{1} / \mathrm{FVC}\right.$ ratio and $\left.\mathrm{FEF}_{25-75 \%}\right)$. As previously described, at baseline, it resulted statistically significant; on the contrary, in the following steps (at T3 and $\mathrm{T} 6$ for $\mathrm{FEV}_{1} / \mathrm{FVC}$ ratio, at $\mathrm{T} 6$ for $\mathrm{FEF}_{25-75} \%$ ), the values became insignificant between the two groups (involvement of 1-2 lobes and 3-6 lobes). This result could be motivated by the response to treatment, influencing both inflammation and hypersecretion.

Comparing the study results with many papers described in literature, there is great heterogeneity regarding the relationship between radiology and clinical-functional aspects of bronchiectasis. In particular, a Chinese study published in 2016 showed the absence of correlation between the extent of bronchiectasis and age, smoking history, BMI, exacerbations in the previous year, $\mathrm{FEV}_{1} / \mathrm{FVC}$ ratio and predicted $\mathrm{FEV}_{1} \%$ in a patient cohort suffering from post-COPD bronchiectasis [14].

In contrast, in 2014, a Korean study found a negative correla- tion between the extent of bronchiectasis and BMI in moderate to severe disease [15]. Patients experienced weight loss as the disease progressed.

The following year, an Italian team carried out a study on neutrophilic bronchial inflammation in NCFB patients. As a result, predicted $\mathrm{FEV}_{1} \%$ was negatively correlated with the number of pulmonary lobes involved in the disease [16].

According to another paper published in 2019, which included bronchiectasis patients performing pulmonary rehabilitation, disease progression seems to be associated with a reduction in exercise capacity $[17,18]$. The 6-minute walk distance correlated with the extent of bronchiectasis on CT scan and was found by McDonnell et al. to reflect disease severity measured by the Bronchiectasis Severity Index (BSI) [18]. Patients with severe disease walked an average of $83 \mathrm{~m}$ less than patients with moderate disease and $198 \mathrm{~m}$ less than those with mild disease [17].

The BSI was set up and validated for bronchiectasis by Chalmers et al. in 2014 [17] . This is a 9-item scale that includes a radiological severity parameter [19]. This is evaluated with the

Table 2. Pulmonary function tests (PFTs) and number of lobes involved in bronchiectasis. Values expressed as mean \pm SD.

\begin{tabular}{|c|c|c|c|c|c|}
\hline & Timing & 1-2 lobes & 3-6 lobes & Difference (95\% C.I.) & Statistical significance \\
\hline FVC\% (\% predicted) & $\begin{array}{c}\text { Baseline (43) } \\
\text { T3 (30) } \\
\text { T6 (20) }\end{array}$ & $\begin{array}{c}78.6 \pm 31.7 \\
79.5 \pm 26 \\
78 \pm 26\end{array}$ & $\begin{array}{l}76.2 \pm 19.6 \\
75 \pm 17.9 \\
62 \pm 15.1\end{array}$ & $\begin{array}{l}-2.34(-18.93 \text { to } 14.25) \\
2.5(-14.72 \text { to } 20.03) \\
-8.75(-26.97 \text { to } 9.74)\end{array}$ & $\begin{array}{l}\text { Not significant } \\
\text { Not significant } \\
\text { Not significant }\end{array}$ \\
\hline $\mathrm{FEV}_{1} \%$ (\% predicted) & $\begin{array}{c}\text { Baseline (43) } \\
\text { T3 (30) } \\
\text { T6 (20) }\end{array}$ & $\begin{array}{l}75.3 \pm 34.4 \\
78.1 \pm 30.8 \\
76.8 \pm 29.2\end{array}$ & $\begin{array}{c}63.6 \pm 20.7 \\
61.6 \pm 19.1 \\
52.8 \pm 18\end{array}$ & $\begin{array}{l}-11.72(-30.18 \text { to } 6.74) \\
-9.79(-28.5 \text { to } 9.01) \\
-12.48(-31.5 \text { to } 6.65)\end{array}$ & $\begin{array}{l}\text { Not significant } \\
\text { Not significant } \\
\text { Not significant }\end{array}$ \\
\hline $\mathrm{FEV}_{1} / \mathrm{FVC}$ ratio & $\begin{array}{c}\text { Baseline (43) } \\
\text { T3 (30) } \\
\text { T6 (20) }\end{array}$ & $\begin{array}{c}76.6 \pm 14.5 \\
77.4 \pm 12.1 \\
79.9 \pm 12\end{array}$ & $\begin{array}{c}68.5 \pm 13.4 \\
68 \pm 12.5 \\
74.1 \pm 13.4\end{array}$ & $\begin{array}{l}-8.16(-16.18 \text { to }-0.14) \\
-8.66(-17.4 \text { to } 0.14) \\
-0.74(-10.26 \text { to } 8.99)\end{array}$ & $\begin{array}{c}\text { Significant } \\
\text { Not significant } \\
\text { Not significant }\end{array}$ \\
\hline $\mathrm{FEF}_{25 \%-75 \%}(\%$ predicted $)$ & $\begin{array}{c}\text { Baseline (43) } \\
\text { T3 (30) } \\
\text { T6 (20) }\end{array}$ & $\begin{array}{c}56.6 \pm 38.3 \\
61.6 \pm 33 \\
59.7 \pm 30.4\end{array}$ & $\begin{array}{c}35.8 \pm 20 \\
31.5 \pm 20.7 \\
34.2 \pm 15.1\end{array}$ & $\begin{array}{c}-20.8(-40.8 \text { to }-0.8) \\
-25.13(-45.57 \text { to }-4.59) \\
-20.41(-41.42 \text { to } 0.7)\end{array}$ & $\begin{array}{c}\text { Significant } \\
\text { Significant } \\
\text { Not significant }\end{array}$ \\
\hline $\mathrm{DL}_{\mathrm{CO}} \%$ (\% predicted) & $\begin{array}{c}\text { Baseline (30) } \\
\text { T3 (27) } \\
\text { T6 (16) }\end{array}$ & $\begin{array}{c}76.5 \pm 24.6 \\
73.9 \pm 20.1 \\
76 \pm 20.8\end{array}$ & $\begin{array}{c}68.4 \pm 16.6 \\
71.2 \pm 22.4 \\
64 \pm 13.2\end{array}$ & $\begin{array}{l}-8.15(-22.82 \text { to } 6.52) \\
-4.78(-19.47 \text { to } 9.7) \\
-9.52(-26.22 \text { to } 7.29)\end{array}$ & $\begin{array}{l}\text { Not significant } \\
\text { Not significant } \\
\text { Not significant }\end{array}$ \\
\hline TLC (\% predicted) & $\begin{array}{c}\text { Baseline (24) } \\
\text { T3 (21) } \\
\text { T6 (13) }\end{array}$ & $\begin{array}{l}150.3 \pm 39.1 \\
137.5 \pm 47.8 \\
138.8 \pm 41.2\end{array}$ & $\begin{array}{c}140.8 \pm 49.2 \\
129.3 \pm 41.2 \\
153.5 \pm 30\end{array}$ & $\begin{array}{c}-3.48(-41.27 \text { to } 34.7) \\
-0.02(-38.35 \text { to } 38.65) \\
-30.1(-71.55 \text { to } 9.94)\end{array}$ & $\begin{array}{l}0.861 \\
0.999 \\
0.171\end{array}$ \\
\hline MI & $\begin{array}{c}\text { Baseline (24) } \\
\text { T3 (21) } \\
\text { T6 (13) }\end{array}$ & $\begin{array}{c}52.8 \pm 11 \\
49 \pm 10.7 \\
57.2 \pm 13.5\end{array}$ & $\begin{array}{c}49.3 \pm 8.02 \\
53 \pm 5.97 \\
52.8 \pm 8.22\end{array}$ & $\begin{array}{l}-3.15(-12.37 \text { to } 6.24) \\
3.91(-6.13 \text { to } 13.85) \\
-4.51(-17.38 \text { to } 8.29)\end{array}$ & $\begin{array}{l}0.531 \\
0.471 \\
0.520\end{array}$ \\
\hline RV\% (\% predicted) & $\begin{array}{c}\text { Baseline (30) } \\
\text { T3 (27) } \\
\text { T6 (16) }\end{array}$ & $\begin{array}{l}83.6 \pm 26.8 \\
77.2 \pm 23.4 \\
88.8 \pm 22.3\end{array}$ & $\begin{array}{c}76.8 \pm 28.6 \\
68.1 \pm 18.6 \\
67 \pm 14.1 \\
\end{array}$ & $\begin{array}{l}-7.16(-25.15 \text { to } 10.67) \\
-8.62(-26.45 \text { to } 9.42) \\
-19.46(-43.03 \text { to } 4.47)\end{array}$ & $\begin{array}{l}\text { Not significant } \\
\text { Not significant } \\
\text { Not significant }\end{array}$ \\
\hline 6MWT (m) & $\begin{array}{c}\text { Baseline (18) } \\
\text { T3 (6) } \\
\text { T6 (4) }\end{array}$ & $\begin{array}{c}181 \pm 196 \\
121 \pm 28 \\
156 \pm 44.1\end{array}$ & $\begin{array}{c}100 \pm 33.9 \\
83.3 \pm 34.3 \\
86 \pm 12\end{array}$ & $\begin{array}{l}-74.23(-197.02 \text { to } 49.21) \\
-82.99(-212.66 \text { to } 43.52) \\
-119.71(-252.38 \text { to } 10.36)\end{array}$ & $\begin{array}{l}\text { Not significant } \\
\text { Not significant } \\
\text { Not significant }\end{array}$ \\
\hline $\mathrm{PaO}_{2}(\mathrm{mmHg})$ & $\begin{array}{l}\text { Baseline (41) } \\
\text { T3 (25) } \\
\text { T6 (15) }\end{array}$ & $\begin{array}{c}76 \pm 14.8 \\
76.6 \pm 13.5 \\
79.8 \pm 5.82 \\
\end{array}$ & $\begin{array}{l}73.5 \pm 10.5 \\
71.3 \pm 12.4 \\
70.3 \pm 7.59\end{array}$ & $\begin{array}{l}-2.48(-10.09 \text { to } 5.13) \\
-2.76(-11.41 \text { to } 6.29) \\
-4.43(-14.81 \text { to } 6.46)\end{array}$ & $\begin{array}{l}\text { Not significant } \\
\text { Not significant } \\
\text { Not significant }\end{array}$ \\
\hline $\mathrm{SaO}_{2}(\%)$ & $\begin{array}{l}\text { Baseline (41) } \\
\text { T3 (25) } \\
\text { T6 (15) }\end{array}$ & $\begin{array}{l}96.6 \pm 3.97 \\
96.5 \pm 2.43 \\
97.6 \pm 1.72\end{array}$ & $\begin{array}{l}96.6 \pm 2.68 \\
96.3 \pm 1.51 \\
84.6 \pm 34.2\end{array}$ & $\begin{array}{c}-0.02(-6.06 \text { to } 6.02) \\
-0.23(-8.06 \text { to } 7.61) \\
-13.03(-27.4 \text { to }+2.67)\end{array}$ & $\begin{array}{l}\text { Not significant } \\
\text { Not significant } \\
\text { Not significant }\end{array}$ \\
\hline $\mathrm{PaCO}_{2}(\mathrm{mmHg})$ & $\begin{array}{c}\text { Baseline (41) } \\
\text { T3 (25) } \\
\text { T6 (15) }\end{array}$ & $\begin{array}{l}41.4 \pm 8.23 \\
39.8 \pm 5.06 \\
39.5 \pm 5.48\end{array}$ & $\begin{array}{c}41 \pm 6.79 \\
41.9 \pm 8.81 \\
42.1 \pm 8.06\end{array}$ & $\begin{array}{c}-0.39(-4.82 \text { to } 4.04) \\
1.12(-3.67 \text { to } 5.84) \\
-1.09(-6.31 \text { to } 4.01)\end{array}$ & $\begin{array}{l}\text { Not significant } \\
\text { Not significant } \\
\text { Not significant }\end{array}$ \\
\hline
\end{tabular}

FVC, forced vital capacity; $\mathrm{FEV}_{1}$, forced expiratory volume in 1 second; $\mathrm{FEF}_{25-750}$, forced expiratory flow at $25-75 \%$ of the vital capacity; $\mathrm{DL}_{\mathrm{c}}$, diffusing capacity of the lung for carbon monoxide (CO); RV, residual volume; TLC, total lung capacity; $\mathrm{MI}$, Motley index; $6 \mathrm{MWT}$, six minute walking test; $\mathrm{PaO} 2$, partial pressure of oxygen; $\mathrm{SaO}_{2}$, arterial oxygen saturation; $\mathrm{PaCO}_{2}$, partial pressure of carbone monoxide $\left(\mathrm{CO}_{2}\right)$. 
modified Reiff score, based on two tomographic parameters: the number of lobes affected by bronchiectasis and the degree of dilation (tubular $=1$, varicose $=2$, and cystic $=3$ ). The maximum score is 18 , and the minimum score is 1 [20].

\section{Conclusions}

HRCT is a key exam in NCFB diagnostics and monitoring. Its role in managing the NCFB is well established both in clinical practice and in the literature. The number of involved lobes seems to represent a useful prognostic index and an important follow up tool.

The study carried out showed a crucial correlation between imaging and the number of exacerbations in the previous year, as well as some functional parameters, $\mathrm{FEV}_{1} / \mathrm{FVC}$ ratio and $\mathrm{FEF}_{25}$ $75 \%$. Regarding the latter, the lack of correlation in the follow up could be associated with an improvement of lung function due to the treatment. In fact, the main strategy in bronchiectasis consists of the prevention and treatment of exacerbations.

Further studies are needed with greater sample size. Furthermore, the prognostic role of $\mathrm{FEF}_{25-75 \%}$ could be investigated, considering its possible inclusion in the scoring systems currently used in the bronchiectasis staging, like the BSI.

However, the best tool to improve disease management is to strengthen GPs' awareness of bronchiectasis. With their collaboration, an early diagnosis will make the treatment faster and more targeted.

\section{References}

1. Chalmers JD, Aliberti S, Blasi F. Management of bronchiectasis in adults. Eur Respir J 2015;45:1446-62.

2. European Respiratory Society. Bronchiectasis. Chapter 15. In: European lung white book. European Respiratory Society; 2018. Available from: https://www.erswhitebook.org/chapters/bronchiectasis/

3. de la Rosa D, Martínez-Garcia MA, Olveira C, Girón R, Máiz L, Prados C. Annual direct medical costs of bronchiectasis treatment: Impact of severity, exacerbations, chronic bronchial colonization, and chronic obstructive pulmonary disease coexistence. Chron Respir Dis 2016;13:361-71.

4. Loebinger MR, Wells AU, Hansell DM, Chinyanganya N, Devaraj A, Meister M, Wilson R. Mortality in bronchiectasis: a long-term study assessing the factors influencing survival. Eur Respir J 2009;34:843-9.

5. Aliberti S, Sotgiu G, Lapi F, Gramegna A, Cricelli C, Blasi F. Prevalence and incidence of bronchiectasis in Italy. BMC Pulm Med 2020;20:15.

6. Juliusson G, Gudmundsson G. Diagnostic imaging in adult non-cystic fibrosis bronchiectasis. Breathe (Sheff) 2019;15:190-7.

7. Martinez-García MA, Oscullo G, Posadas T, Zaldivar E, Villa C, Dobarganes Y, et al. Pseudomonas aeruginosa and lung function decline in patients with bronchiectasis. Clin Microbiol Infect 2021;27:428-34.

8. Huang HY, Sheng TF, Lin CW, Wang TW, Lo CY, Chung FT, et al. Oxygen desaturation during the 6-min walk test as a risk for osteoporosis in non-cystic fibrosis bronchiectasis. BMC Pulm Med 2019;19:28.

9. Pino Peña I, Cheplygina V, Paschaloudi S, Vuust M, Carl J, Møller Weinreich U, et al. Automatic emphysema detection using weakly labeled HRCT lung images. PLoS One 2018;13:e0205397. Erratum in: PLoS One 2019; 14:e0220873.

10. R Core Team. R. A language and environment for statistical computing. R Foundation for Statistical Computing: Vienna; 2020. Available from: https://www.r-project.org/

11. Miller MR, Crapo R, Hankinson J, Brusasco V, Burgos F, Casaburi R, et al. General considerations for lung function testing. Eur Respir J 2005;26:153-61.

12. Piatti G, De Santi MM, Farolfi A, Zuccotti GV, D'Auria E, Patria MF, et al. Exacerbations and Pseudomonas aeruginosa colonization are associated with altered lung structure and function in primary ciliary dyskinesia. BMC Pediatr 2020;20:158.

13. Costa JC, Machado JN, Ferreira C, Gama J, Rodrigues C. The Bronchiectasis Severity Index and FACED score for assessment of the severity of bronchiectasis. Pulmonology 2018;24:149-54.

14. Jin J, Yu W, Li S, Lu L, Liu X, Sun Y. Factors associated with bronchiectasis in patients with moderate-severe chronic obstructive pulmonary disease. Medicine (Baltimore) 2016;95:e4219.

15. Bak SH, Kim S, Hong Y, Heo J, Lim MN, Kim WJ. Quantitative computed tomography features and clinical manifestations associated with the extent of bronchiectasis in patients with moderate-to-severe COPD. Int J Chron Obstruct Pulmon Dis 2018;13:1421-31.

16. Dente FL, Bilotta M, Bartoli ML, Bacci E, Cianchetti S, Latorre M, et al. Neutrophilic bronchial inflammation correlates with clinical and functional findings in patients with noncystic fibrosis bronchiectasis. Mediators Inflamm 2015;2015:642503.

17. Chalmers JD, Crichton ML, Brady G, Finch S, Lonergan M, Fardon TC. Pulmonary rehabilitation after exacerbation of bronchiectasis: a pilot randomized controlled trial. BMC Pulm Med 2019;19:85.

18. McDonnell MJ, Aliberti S, Goeminne PC, Dimakou K, Zucchetti SC, Davidson J, et al. Multidimensional severity assessment in bronchiectasis: an analysis of seven European cohorts. Thorax 2016;71:1110-8.

19. He M, Zhu M, Wang C, Wu X, Xiong X, Wu H, et al. Prognostic performance of the FACED score and bronchiectasis severity index in bronchiectasis: a systematic review and meta-analysis. Biosci Rep 2020;40:BSR20194514.

20. Chalmers JD, Goeminne P, Aliberti S, McDonnell MJ, Lonni $\mathrm{S}$, Davidson J, et al. The bronchiectasis severity index. An international derivation and validation study. Am J Respir Crit Care Med 2014;189:576-85.

Received for publication: 8 June 2021. Accepted for publication: 28 September 2021.

This work is licensed under a Creative Commons Attribution-NonCommercial 4.0 International License (CC BY-NC 4.0).

(C) Copyright: the Author(s), 2021

Licensee PAGEPress, Italy

Multidisciplinary Respiratory Medicine 2021; 16:791

doi:10.4081/mrm.2021.791 